\title{
Изучение закономерностей фазовых превращений, происходящих при образовании керамических пигментов на основе высокомагнезиальных пород Карелии
}

\author{
Попова Т.В., Инина И.С. \\ Институт геологии КарНЦ РАН, Петрозаводск, tророvа@krc.karelia.ru
}

\begin{abstract}
Аннотация. Изучена возможность получения керамических пигментов на основе серпентинитов разного минерального состава и оксидов переходных элементов: $\mathrm{CoO}, \mathrm{NiO}, \mathrm{Cr}_{2} \mathrm{O}_{3}, \mathrm{MnO}_{2}$. Показано, что на основе серпентинитов разного генезиса и оксидов $\mathrm{CoO}, \mathrm{NiO}, \mathrm{MnO}_{2}$ могут быть получены керамические пигменты, основная хромофорная фаза которых имеет структуру оливина. В керамических пигментах, полученных на основе апоультрамафитовых серпентинитов, присутствуют две хромофорные фазы: оливин, содержащий введенные катионы-хромофоры, а также магнетит. В керамических пигментах, полученных на основе апокарбонатных серпентинитов, хромофорной фазой является оливин, содержащий введенные катионы-хромофоры.

Ключевые слова: серпентинит, керамический пигмент, ортосиликат кобальта, ортосиликат никеля, серпентин, оливин.
\end{abstract}

\section{The study of phase transformations occurring upon the formation of ceramic pigments based on high-magnesian rocks of Karelia}

\author{
Popova T.V., Inina I.S. \\ Institute of GeologyKRC RAS, Petrozavodsk, tpopova@krc.karelia.ru
}

\begin{abstract}
The possibility of producing ceramic pigments based on serpentinites of varying mineral compositions and the transitional element oxides $\mathrm{CoO}, \mathrm{NiO}, \mathrm{Cr}_{2} \mathrm{O}_{3}$ and $\mathrm{MnO}_{2}$ was studied. It was shown that ceramic pigments, whose major chromophore phase displays an olivine structure, can be synthesized on the basis of genetically different serpentinites and the oxides $\mathrm{CoO}, \mathrm{NiO}$ and $\mathrm{MnO}_{2}$. Ceramic pigments, based on apoultramafic serpentinites, contain two chromophore phases: olivine, which contains introduced cations-chromophores, and magnetite. Olivine, containing introduced cations-chromophores, is a chromophore phase in ceramic pigments based on apocarbonate serpentinites.
\end{abstract}

Key words: serpentinite, ceramic pigment, cobalt orthosilicate, nickel orthosilicate, serpentine, olivine.

\section{Введение}

С целью расширения сферы использования высокомагнезиального сырья Карелии в создании продукции в различных отраслях промышленности выполнено исследование возможности получения керамических пигментов на основе серпентинитов разного минерального состава.

Керамические пигменты - жаропрочные неорганические соединения, окрашенные в различные цвета. Окраска пигментов создается благодаря катионам переходных и редкоземельных элементов и обусловлена поглощением света либо за счет d-d-переходов электронов, либо за счет переноса заряда. Керамические пигменты используются в разных направлениях: в производстве керамической плитки, фарфоровых изделий, изразцов, архитектурно-строительной керамики, сухих строительных смесей. Для синтеза керамических пигментов в качестве хромофоров чаще всего используют соединения, содержащие Ti, V, Cr, Mn, Fe, Co, Ni, Cu и др. (Масленникова и др.,2009).

Производство керамических пигментов требует больших затрат, так как связано с высокотемпературным синтезом $\left(1300-1400^{\circ} \mathrm{C}\right)$ и с необходимостью использовать дорогое, редкое, высокосортное сырьё, большей частью химреактивы, часть которых токсичны.Использование нетрадиционных сырьевых материалов - природного минерального сырья и техногенных отходов - позволяет снизить температуру синтеза пигментов, уменьшить затраты на производство, а также более полно и комплексно использовать промышленные отходы (Седельникова и др., 2014).

Серпентиниты - метаморфические горные породы, содержащие более 75 \% серпентина. На основе серпентинитов (или серпентинов) до сих пор не были получены керамические пигменты, 
при том, что они являются повсеместно распространенным дешевым сырьем, которое довольно часто отправляется в отходы при добыче разных руд.

Серпентины - минералы группы слоистых силикатов общей формулой $(\mathrm{Mg}, \mathrm{Fe})_{3} \mathrm{Si}_{2} \mathrm{O}_{5}(\mathrm{OH})_{4}$. Основными разновидностями серпентина являются: лизардит, хризотил и антигорит. При термообработке лизардит и хризотил разлагаются в области $600-700^{\circ} \mathrm{C}$, антигорит $-700-800^{\circ} \mathrm{C}$. При этом образуется форстерит и выделяется некоторое количество аморфной фазы состава энстатита, обогащенной кремнеземом, причем эта фаза существует без кристаллизации до температуры примерно $820^{\circ} \mathrm{C}$, при которой происходит ее кристаллизация (Gualtieri et al., 2012).

\section{Методы и материалы}

Для исследований использована проба апоультрамафитовых серпентинитов Светлоозерского месторождения (СВС-4) следующего состава (мас. \%): антигорит - 79, магнетит - 13, магнезит - 8, а также проба апокарбонатных серпентинитов из керна скважины Ветреного Пояса (ВП-1), состоящая из 50 мас. \% брусита и 50 мас. \% хризотила. (Пробы предоставлены сотрудниками ИГКарНЦРАН П.В.Фроловым и А.Е.Ромашкиным).

Исходные пробы и полученные продукты исследовались следующими методами:

- Оптическая и сканирующая электронная микроскопия,

- Рентгенофазовый и рентгеноструктурный анализ (дифрактометр ARL X'TRA с излучением $\mathrm{CuK} \alpha$ в области углов $\left.2 \Theta=2-90^{\circ}\right)$,

- Рентгеноспектральный микроанализ (микроанализатор INCA Energy 350 на базе сканирующего микроскопа VEGA II LSH),

- Термография (ДСК - ДТГ) в интервале температур 20-1200 (синхронный термический анализатор STA 449 F1 Jupiter фирмы NETZSCH), навеска массой 10 мг.

Пигменты получались по следующей схеме: измельчение пробы до крупности -70 мкм; составление шихты (проба + оксид-хромофор $\mathrm{CoO}, \mathrm{MnO}_{2}, \mathrm{Cr}_{2} \mathrm{O}_{3}, \mathrm{NiO}$ ); перемешивание в механической мельнице; обжиг в муфельной печи.

\section{Экспериментальные результаты}

Как показал термографический анализ, разложение хризотила с выделением структурной воды происходит в области температур 600-625 ${ }^{\circ} \mathrm{C}$, антигорита $-700-740{ }^{\circ} \mathrm{C}$, после чего следует кристаллизация энстатита около $810-820^{\circ} \mathrm{C}$. Кроме того, в области $350-430^{\circ} \mathrm{C}$ разлагается брусит (проба ВП-1), в области 500-550 C - магнезит (проба СВС-4). (Интерпретация термограмм выполнена на основе справочника (Иванова и др., 1974)).

Как показал рентгенофазовый анализ, при термообработке пробы СВС-4 в области температур 900- $1100^{\circ} \mathrm{C}$ без оксидов-хромофоров (холостая проба) образуются оливин, энстатит, гематит и магнетит, при $1200^{\circ} \mathrm{C}$ регистрируется протоэнстатит. Фазовый состав обожженных при $1200^{\circ} \mathrm{C}$ образцов с добавками разных оксидов различается в зависимости от вида и количества введенного оксида (см. табл. 1). Добавка оксида хрома не приводит к фазовым изменениям по сравнению с холостой пробой (кроме присутствия $\mathrm{Cr}_{2} \mathrm{O}_{3}$ ).

На рентгенограммах образцов с добавками оксидов $\mathrm{Co}, \mathrm{Ni}, \mathrm{Mn}$, обожженных при температуре $1200^{\circ} \mathrm{C}$, отсутствуют пики этих оксидов, а также уменьшается интенсивность пиков протоэнстатита $\left(\mathrm{d}=3.17 \AA\left(2 \Theta=28.1^{\circ}\right)\right.$ и $\left.2.88 \AA\left(2 \Theta=31^{\circ}\right)\right)$ по сравнению с холостой пробой, причем при увеличении количества оксида свыше $20 \%$ протоэнстатит исчезает полностью в случае $\mathrm{CoO}$ и $\mathrm{NiO}$, в случае $\mathrm{MnO}_{2}$ - остается в небольшом количестве (рентгенограммы с СоО представлены на рис.1). Одновременно с этим наблюдается изменение интенсивности пиков оливина: пик при $\mathrm{d}=2.77 \AA\left(2 \Theta=32.3^{\circ}\right)$ по интенсивности становится сравним с пиками при $\mathrm{d}=2.52\left(2 \Theta=35.8^{\circ}\right)$ и $2.46 \AA\left(2 \Theta=36.5^{\circ}\right)$. Как

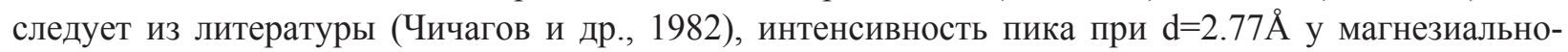
железистого оливина увеличивается по мере увеличения содержания железа, изоморфно замещающего магний. Данный факт объясняется тем, что линия с $\mathrm{d}=2.77 \AA$ является отражением от плоскости кристалла оливина (130), на которой расположены катионы $\mathrm{Mg}$, а также катионы, изоморфно замещающие его. Таким образом, усиление этого пика в образцах с добавкой $\mathrm{CoO}, \mathrm{NiO}, \mathrm{MnO}_{2}$ с од 
Таблица 1. Фазовый состав термообработанных образцов $\left(\mathrm{T}=1200^{\circ} \mathrm{C}\right)$.

Table 1. Phase composition of calcined samples $\left(\mathrm{T}=1200^{\circ} \mathrm{C}\right)$.

\begin{tabular}{|l|l|}
\hline \multicolumn{1}{|c|}{ Образец } & \multicolumn{1}{|c|}{ Фазовый состав } \\
\hline $\mathrm{CBC}-4$ холостая & Оливин, протоэнстатит, гематит, магнетит \\
\hline $\mathrm{CBC}-4+5 \% \mathrm{Cr}_{2} \mathrm{O}_{3}$ & Оливин, протоэнстатит, гематит, магнетит, $\mathrm{Cr}_{2} \mathrm{O}_{3}$ \\
\hline $\mathrm{CBC}-4+5 \% \mathrm{CoO}$ & Оливин, протоэнстатит, гематит, магнетит \\
\hline $\mathrm{CBC}-4+20 \% \mathrm{CoO}$ & Оливин, магнетит \\
\hline $\mathrm{CBC}-4+30 \% \mathrm{CoO}$ & Оливин, магнетит \\
\hline $\mathrm{CBC}-4+5 \% \mathrm{MnO}_{2}$ & Оливин, протоэнстатит, гематит, магнетит \\
\hline $\mathrm{CBC}-4+20 \% \mathrm{MnO}_{2}$ & Оливин, немного протоэнстатита, магнетит \\
\hline $\mathrm{CBC}-4+5 \% \mathrm{NiO}$ & Оливин, протоэнстатит, гематит, магнетит \\
\hline $\mathrm{BП-1} \mathrm{холостая}$ & Оливин, периклаз, магнетит \\
\hline $\mathrm{BП-1+20 \%} \mathrm{NiO}$ & Оливин, оксид Мg-Ni, магнетит \\
\hline $\mathrm{BП-1+20 \%} \mathrm{CoO}$ & Оливин, оксид Mg-Со, магнетит \\
\hline
\end{tabular}

новременным исчезновением пиков протоэнстатита можно объяснить реакцией оксидов и аморфного энстатита с образованием оливина, часть позиций магния в котором занимают катионы $\mathrm{Co}, \mathrm{Ni}, \mathrm{Mn}$, соответственно (см. реакции (1) - разложение серпентина, (2) - образование оливина). Железо в оливине, по нашему мнению, также присутствует, т.к. оно входило в состав исходного серпентина и, хотя при разложении серпентина часть железа выделилась в виде магнетита, но часть, видимо, осталась в структуре новообразованного оливина, что подтверждается результатами сканирующей электронной микроскопии. При использовании $\mathrm{MnO}_{2}$ имеет место также заметный сдвиг дифракционных пиков новообразованного оливина в сторону увеличения межплоскостных расстояний $\mathrm{d}$, что можно объяснить большим эффективным радиусом катиона марганца по сравнению с катионами магния, кобальта и никеля $\left(\mathrm{Mg}^{2+}-0.74 \AA ; \mathrm{Co}^{2+}-0.74 \AA ; \mathrm{Mn}^{2+}-0.91 \AA ; \mathrm{Ni}^{2+}-0.69 \AA\right)$.

$$
\begin{aligned}
& (\mathrm{Mg}, \mathrm{Fe})_{3} \mathrm{Si}_{2} \mathrm{O}_{5}(\mathrm{OH})_{4}=(\mathrm{Mg}, \mathrm{Fe})_{2} \mathrm{SiO}_{4}+(\mathrm{Mg}, \mathrm{Fe}) \mathrm{SiO}_{3}+2 \mathrm{H}_{2} \mathrm{O} \\
& (\mathrm{Mg}, \mathrm{Fe}) \mathrm{SiO}_{3}+\mathrm{MeO}=(\mathrm{Mg}, \mathrm{Fe}, \mathrm{Me})_{2} \mathrm{SiO}_{4}, \text { где } \mathrm{Me}-\mathrm{Co}, \mathrm{Ni}, \mathrm{Mn}
\end{aligned}
$$

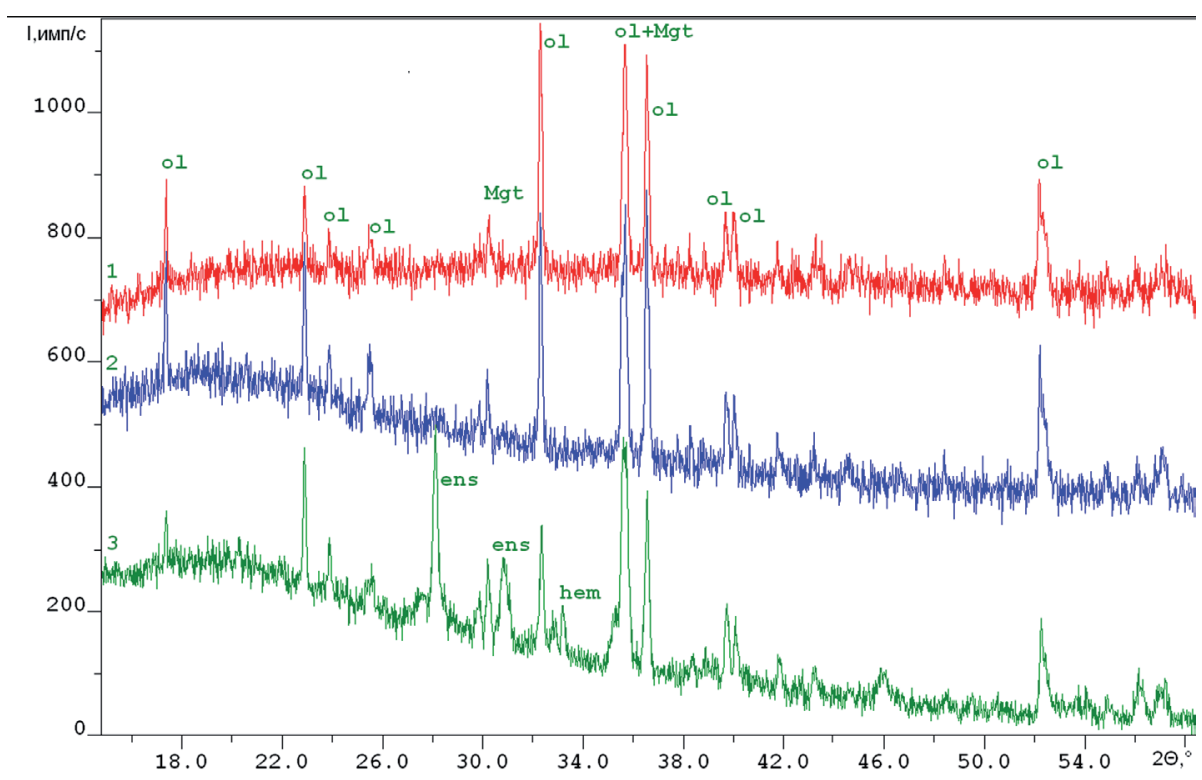

Рис. 1. Рентгенограммы обожженных при $1200^{\circ} \mathrm{C}$ образцов пробы СВС-4.

1 - с добавкой $30 \% \mathrm{CoO}, 2$ - с добавкой $20 \% \mathrm{CoO}, 3$ - холостая проба (без добавок).

Fig. 1. X-ray diffraction patterns of samples calcined at $1200^{\circ} \mathrm{C}$.

$1-30 \% \mathrm{CoO}$ added, $2-20 \% \mathrm{CoO}$ added, 3 - without additional oxide. 
Анализ параметров элементарной ячейки новообразованного оливина (см. табл. 2) показывает, что из серпентина с добавкой оксидов Со, Мn образуется оливин с бо́льшими значениями параметров элементарной ячейки, чем в холостой пробе, с добавкой оксида $\mathrm{Ni}-\mathrm{c}$ меньшими. Наиболее сильно увеличивается параметр $b$, что также является свидетельством образования единой оливиновой фазы из продуктов разложения серпентина и оксидов Сo, Mn, в которой часть позиций магния занимают катионы Co, Mn соответственно, что и приводит к увеличению параметров элементарной ячейки оливина. Величины изменений параметров при введении разных катионов согласуются с таковыми, приведенными в справочнике (Чичагов и др., 1982) для соединений ряда твердых растворов форстерит - ортосиликат кобальта, форстерит - ортосиликат никеля, форстерит - фаялит.

Полученный в результате выполненных экспериментов оливин имеет темный цвет вследствие того, что его зерна пронизаны большим количеством включений гематита (образовавшегося из исходного магнетита при нагревании) и магнетита, который образовался за счет железа, высвободившегося при разложении серпентина. Таким образом, полученный продукт можно использовать в качестве керамического пигмента коричневого цвета - при добавлении $\mathrm{NiO}$, темно-коричневого цвета $-\mathrm{MnO}_{2}$, черного - $\mathrm{CoO}$. Для того, чтобы получить керамические пигменты более разнообразной цветовой гаммы, необходимо выполнить обогатительные операции для удаления магнетита, как предварительно, так и после обжига. Выделенный магнетит при этом также может быть использован как коричневый керамический пигмент.

Таблица 2. Параметры элементарной ячейки оливина.

Table 2. Olivine Unit Cell Parameters.

\begin{tabular}{|l|c|c|c|c|}
\hline \multicolumn{1}{|c|}{ Образец } & $\mathrm{a} \pm \Delta \mathrm{a}, \AA$ & $\mathrm{b} \pm \Delta \mathrm{b}, \AA$ & $\mathrm{c} \pm \Delta \mathrm{c}, \AA$ & $\mathrm{V}, \AA^{3}$ \\
\hline СВC-4 & $\mathbf{4 . 7 4 1} \pm \mathbf{0 . 0 0 2}$ & $\mathbf{1 0 . 1 8 0} \pm \mathbf{0 . 0 0 3}$ & $\mathbf{5 . 9 6 9} \pm \mathbf{0 . 0 0 3}$ & $\mathbf{2 8 8 . 1 3}$ \\
\hline $\mathrm{CBC}-4 \mathrm{MnO}_{2} 5 \%$ & $4.743 \pm 0.003$ & $10.211 \pm 0.006$ & $5.981 \pm 0.003$ & 289.66 \\
\hline $\mathrm{CBC} 4 \mathrm{NiO} 5 \%$ & $4.738 \pm 0.004$ & $10.178 \pm 0.003$ & $5.968 \pm 0.002$ & 287.84 \\
\hline $\mathrm{CBC}-4 \mathrm{CoO} 5 \%$ & $4.753 \pm 0.001$ & $10.200 \pm 0.002$ & $5.978 \pm 0.001$ & 289.83 \\
\hline $\mathrm{CBC}-4 \mathrm{CoO} 30 \%$ & $4.763 \pm 0.001$ & $10.229 \pm 0.001$ & $5.985 \pm 0.001$ & 291.6 \\
\hline BП-1 & $\mathbf{4 . 7 5 2} \pm \mathbf{0 . 0 0 1}$ & $\mathbf{1 0 . 2 0 0} \pm \mathbf{0 . 0 0 2}$ & $\mathbf{5 . 9 8 3} \pm \mathbf{0 . 0 0 1}$ & $\mathbf{2 8 9 . 9 8}$ \\
\hline ВП-1 СoO 20\% & $4.753 \pm 0.001$ & $10.203 \pm 0.002$ & $5.974 \pm 0.001$ & 289.69 \\
\hline ВП-1 СоO 13\% & $4.754 \pm 0.001$ & $10.208 \pm 0.002$ & $5.976 \pm 0.001$ & 289.69 \\
\hline
\end{tabular}

В составе пробы апокарбонатного серпентинита ВП-1 почти отсутствует железо: магнетита нет, а в хризотиле его содержится менее $1 \%$. По результатам рентгенофазового анализа, при термообработке пробы ВП-1 без оксидов-хромофоров при температурах $1100-1200^{\circ} \mathrm{C}$ образуются оливин (форстерит), периклаз, немного магнетита (табл.1).

На рентгенограммах образцов с добавками оксидов $\mathrm{CoO}$ и $\mathrm{NiO}$, обожженных при температу$\operatorname{pax} 1100-1200^{\circ} \mathrm{C}$, пик при $\mathrm{d}=2.77 \AA\left(2 \Theta=32.3^{\circ}\right)$ сравним $(\mathrm{c} \mathrm{NiO})$ и даже больше (c $\left.\mathrm{CoO}\right)$ по интенсивности с пиками при $\mathrm{d}=2.52\left(2 \Theta=33.8^{\circ}\right)$ и $2.46 \AA\left(2 \Theta=36.5^{\circ}\right)$, хотя в данной пробе этот эффект выражен не так сильно, как в СВC-4 (см. рис. 2). Объяснение наблюдаемых результатов аналогично пробе CBC-4: происходит образование магнезиально-кобальтового и магнезиально-никелевого оливина, соответственно. Часть введенного оксида кобальта образует смешанный оксид магниякобальта, что подтверждается изменениями на рентгенограмме: интенсивность пика периклаза при $\mathrm{d}=2.44 \AA\left(2 \Theta=37^{\circ}\right)$ существенно меньше по сравнению с пиком при $\mathrm{d}=2.11 \AA\left(2 \Theta=42.9^{\circ}\right)$, а у смешанного магнезиально-кобальтового оксида интенсивности данных пиков сопоставимы, что наблюдается и в нашем случае. Образование смешанного оксида магния-никеля также имеет место (интенсивность пика при $\mathrm{d}=2.44 \AA$ также возрастает, но в меньшей степени, чем с $\mathrm{CoO}$ ). Кроме того, на рентгенограмме пробы с $\mathrm{CoO}$ пики смешанного оксида сдвинуты в сторону больших межплоскостных расстояний по сравнению с периклазом (в пробе с оксидом никеля подобного не наблюдалось) (см. рис. 2). Исследования, выполненные методом сканирующей электронной микроскопии, также подтверждают образование смешанных оксидов. Таким образом, в данных образцах, возможно, 


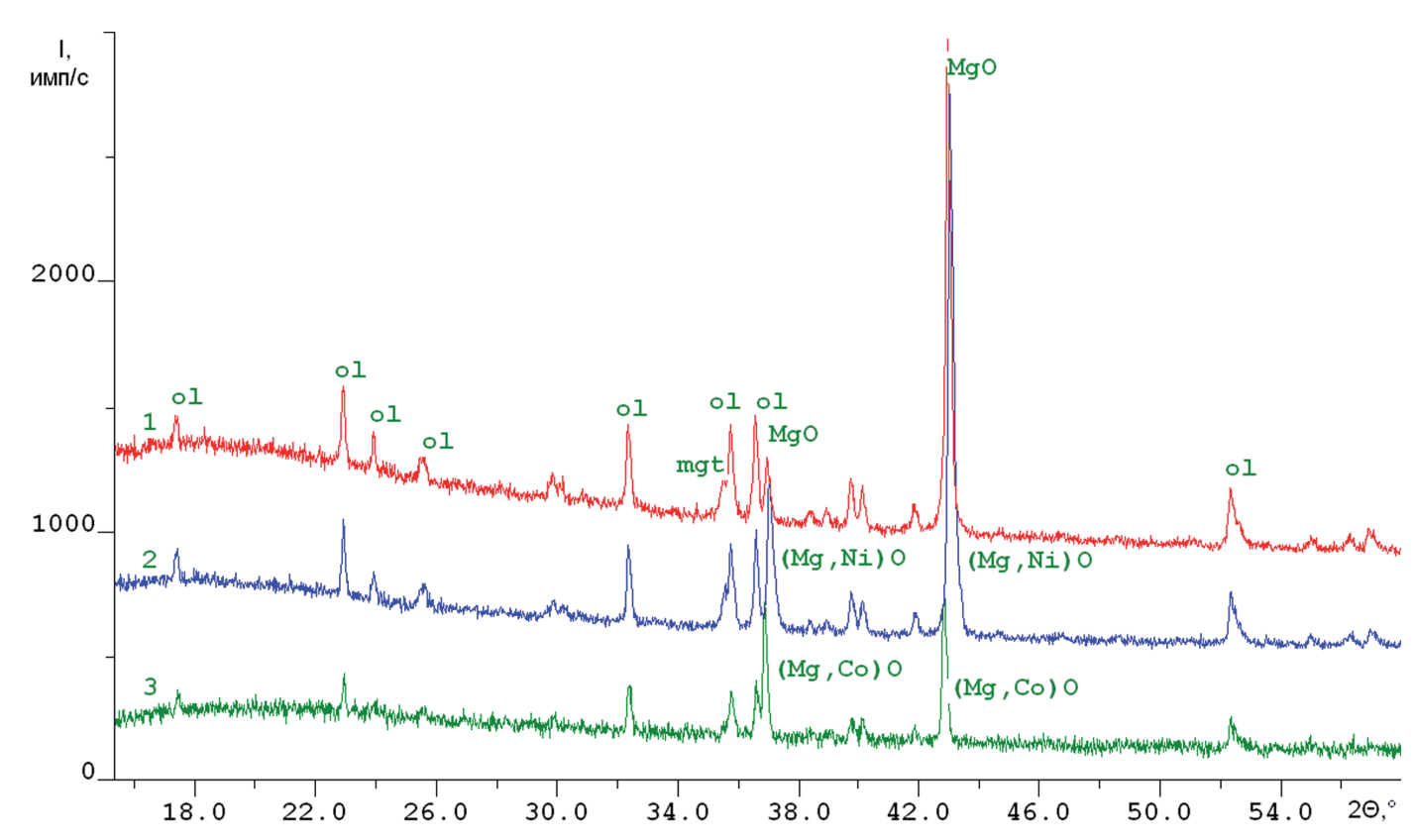

Рис. 2. Рентгенограммы обожженных при $1200^{\circ} \mathrm{C}$ образцов пробы ВП-1. 1 - холостая проба (без добавок), 2 - с добавкой $20 \% \mathrm{NiO}, 3$ - с добавкой $20 \% \mathrm{CoO}$ ).

Fig. 2. X-ray diffraction patterns of samples ВП-1 calcined at $1200^{\circ} \mathrm{C}$. 1 - withou additional oxide, $2-20 \% \mathrm{NiO}$ added, $3-20 \% \mathrm{CoO}$ added.

присутствуют по две хромофорные фазы - магнезиально-кобальтовый оливин и смешанный оксид кобальта-магния, либо магнезиально-никелевый оливин и смешанный оксид никеля-магния.

Анализ параметров элементарной ячейки новообразованных оливинов (см. табл. 2) в данном случае не выявил заметных различий между оливином холостой пробы и проб с оксидамихромофорами. Возможно, это связано с тем, что в холостой пробе фазовый переход аморфного энстатита в оливин происходит вследствие его реакции с оксидом магния, образовавшемся из разложившегося брусита, а в пробах с добавками оксидов Со и $\mathrm{Ni}-$ одновременно и с оксидом магния, и с оксидами-добавками. Концентрации $\mathrm{CoO}$ и $\mathrm{NiO}$ в новообразованном оливине, определенные методом рентгеноспектрального микроанализа, в данной серии экспериментов не превышают $10 \%$ для $\mathrm{CoO}, 5 \%$ - NiO, в то время как в серии экспериментов на основе пробы CBC-4 - достигают $10 \%$ - для $\mathrm{NiO}, 20 \%$ - СоО. Цвет магнезиально-кобальтового оливина - розовый, магнезиальноникелевого - светло-светло-зеленый, что объясняется нахождением катионов Со и Ni в октаэдрической координации.

Таким образом, на основе как апоультрамафитового, так и апокарбонатного серпентинита получены оливины, содержащие в своей структуре катионы-хромофоры $\mathrm{Ni}, \mathrm{Co}, \mathrm{Mn}$. Поскольку оливин - жаростойкий минерал, то можно предполагать, что полученные материалы могут быть использованы в качестве керамических пигментов.

\section{Выводы}

1. На основе серпентинитов разного минерального состава могут быть получены керамические пигменты, основная хромофорная фаза которых имеет структуру оливина.

2. В керамических пигментах, полученных на основе апоультрамафитовых серпентинитов, окраска образуется за счет комбинации хромофорных фаз: оливина, содержащего введенные катионы-хромофоры, гематита, а также магнетита.

3. В керамических пигментах, полученных на основе апокарбонатных серпентинитов, основной хромофорной фазой является оливин, содержащий введенные катионы-хромофоры, также возможно образование дополнительных хромофорных фаз, образующихся за счет разлагающихся карбонатных минералов или брусита. 
Исследования выполнены с использованием оборудования ЦКП КарНЦ РАН.

Работа выполнена в рамках темы НИР ИГ КарНЦ РАН № 0000-018-118020290175-2.

\section{Литература}

1. Иванова В. П. и др. Термический анализ минералов и горных пород. Л.:Недра, 1974. 399 с.

2. Масленникова Т.Н., Пищ И.В. Керамические пигменты. 2-е изд. М. Изд-во: ООО РИФ «Стройматериалы». 2009. 224 с.

3. Седельникова М.Б., Погребенков В.М. Керамические пигменты на основе природного и техногенного минерального сырья. Томск. Изд-во: ТПУ. 2014. 261 с.

4. Чичагов А.В., Сипавина Л.В. Рентгенометрические параметры твердых растворов. М. Изд-во: Наука. 1982. 172c.

5. Gualtieri A.F., Giacobbe C., Viti C. The dehydroxylation of serpentine group minerals // American Mineralogist. 2012. N. 97(4). P. 666-680. DOI:10.2138/am.2012.3952. 